\title{
Bilateral Retinal Detachments Caused by Severe Preeclampsia Diagnosed with Point-of-Care Ultrasound
}

\author{
Jordan Chenkin, MD, MEd*t; Claire L. Heslop, MD, PhDt; Cori R. Atlin, MDt; \\ Michael Romano, MDt; Tomislav Jelic, MD*
}

\section{ABSTRACT}

Bilateral retinal detachments are a rare complication of preeclampsia. We present a case report of a patient with an unknown pregnancy who presented with acute bilateral vision loss and elevated blood pressure. Pointof-care ocular ultrasound revealed bilateral retinal detachments. She was diagnosed with severe preeclampsia and taken for an urgent caesarean section with the delivery of a 26-week-old infant.

\section{RÉSUMÉ}

Le décollement bilatéral de la rétine est une complication rare de la prééclampsie. Sera exposé ici le cas d'une femme enceinte mais ignorante de son état, examinée pour une perte bilatérale aiguë de la vision et une pression artérielle élevée. Une échographie de l'œil, effectuée au lieu d'intervention a révélé un décollement bilatéral de la rétine. Un diagnostic de prééclampsie grave a été posé, et on a procédé à une césarienne d'urgence pour extraire un fotus de 26 semaines.

Keywords: preeclampsia, retinal detachment, ultrasonography

\section{CASE}

A 38-year-old woman presented to the ambulatory section of the ED complaining of bilateral vision loss. She stated that her vision was normal until that morning, when she awoke with blurry vision in both eyes. She denied any scotomas, had no flashes or floaters, and had no past history of visual problems. She reported a mild headache for the past two weeks, which she stated was not unusual for her. She had no abdominal pain, cramping, or vaginal bleeding. Her past medical history was unremarkable, and she was on no medications. She stated that her last menstrual period was four weeks prior, and her cycle had been regular prior to that. She had one previous uncomplicated pregnancy 10 years ago, delivered spontaneously. She denied being pregnant and stated she last had sexual intercourse six months prior to her presentation.

On examination, the patient was a well-appearing $70 \mathrm{~kg}$ female (Body Mass Index 27). Her vital signs were as follows: pulse rate of 86 beats per minute, blood pressure of $227 / 155 \mathrm{~mm} \mathrm{Hg}$, respiratory rate of 18 breaths per minute, temperature of $36.9^{\circ} \mathrm{C}\left(98.4^{\circ} \mathrm{F}\right)$, and oxygen saturation of $96 \%$ on room air. Visual acuity in the right eye was finger-counting at two feet, and 20/200 in the left eye. Her pupils were equal and reactive to light, with no relative afferent pupillary defect and no visual field defect. Cranial nerve examination and peripheral neurologic examination were unremarkable. Cardiorespiratory examination was normal and there was no peripheral edema. Fundoscopy was indeterminate, therefore we proceeded with pointof-care ultrasound (POCUS) examination of both eyes, which revealed bilateral retinal detachments (Figure 1).

Based on these findings, blood work and urinalysis were ordered. Laboratory analysis revealed the following: hemoglobin $126 \mathrm{~g} / \mathrm{L}$ (normal 115-165), white blood cell count $13.3 \times 10^{9} / \mathrm{L}$ (normal $4-11$ ), platelets $67 \times 10^{9} / \mathrm{L}$ (normal $150-400$ ), creatinine $163 \mu \mathrm{mol} / \mathrm{L}$ (normal <106), alkaline phosphatase (ALP) $145 \mathrm{U} / \mathrm{L}$ (normal <120), alanine aminotransferase (ALT) $15 \mathrm{U} / \mathrm{L}$ (normal $<31$ ), aspartate aminotransferase (AST) $46 \mathrm{U} / \mathrm{L}$ (normal $<31$ ), and uric acid $437 \mu \mathrm{mol} / \mathrm{L}$ (normal $<420$ ). The quantitative serum human chorionic gonadotropin (HCG) was 56,516 IU/L and there

From the *Sunnybrook Health Sciences Centre, Toronto, ON; and tUniversity of Toronto, Toronto, ON.

Correspondence to: Jordan Chenkin, 2075 Bayview Avenue, C753, Toronto, ON, M4N 3M5; Email: Jordan.chenkin@utoronto.ca 


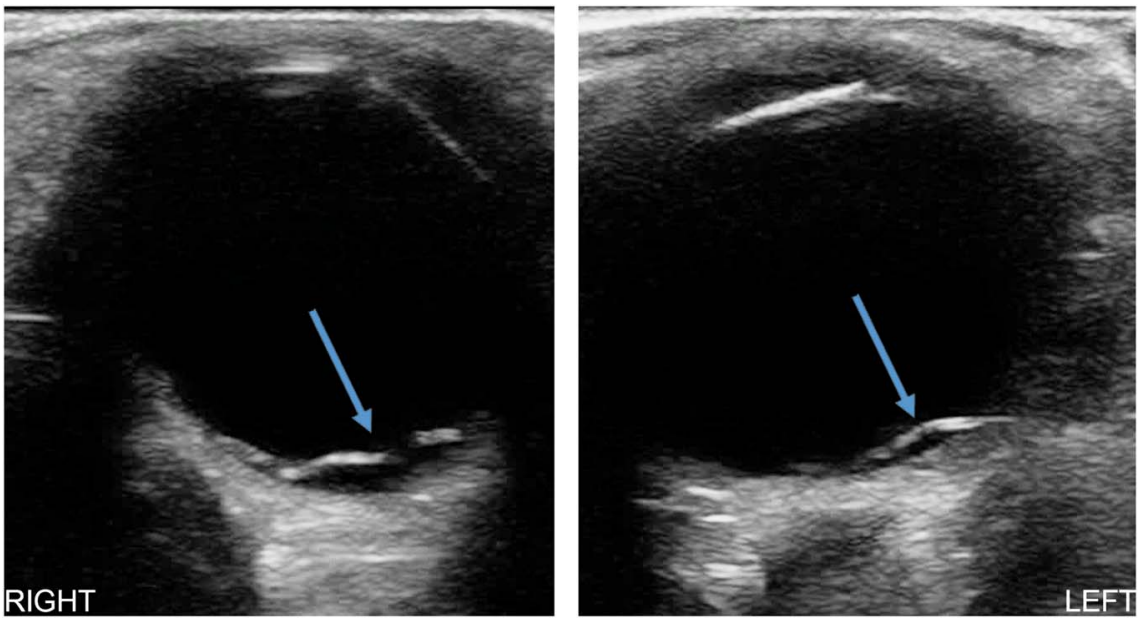

Figure 1. Point-of-care ultrasound demonstrating bilateral retinal detachments (arrows), appearing as bright lines protruding into the vitreous body and attaching posteriorly to the optic nerve.

was $2+$ proteinuria on urine dipstick. The remainder of her laboratory tests, including electrolytes, bilirubin, and coagulation tests, were within normal limits. A peripheral blood smear was negative for hemolysis.

A POCUS examination of the abdomen revealed a live intra-uterine fetus with a heart rate of 160 beats per minute and a biparietal diameter consistent with a 26-week gestation. Based on these findings, we diagnosed the patient with severe preeclampsia. She was started on IV magnesium sulfate and IV labetalol. Obstetrics was consulted and the patient was taken for an urgent caesarean section delivery. A dilated fundoscopic examination performed by ophthalmology subsequently confirmed the diagnosis of bilateral exudative retinal detachments. Within two weeks of delivery, her visual acuity had returned to normal without any further treatment. Furthermore, the infant was stable and doing well in the neonatal intensive care unit.

\section{DISCUSSION}

This case highlights the association between unusual visual complaints and the diagnosis of preeclampsia. Preeclampsia is a systemic disorder that complicates approximately $2 \%-8 \%$ of pregnancies and is associated with significant maternal and fetal morbidity and mortality. ${ }^{1}$ The diagnostic criteria for preeclampsia include: gestational hypertension (systolic blood pressure $\geq 140 \mathrm{~mm} \mathrm{Hg}$ or diastolic blood pressure $\geq 90 \mathrm{~mm} \mathrm{Hg}$, onset after 20 weeks gestational age), plus either proteinuria or end-organ dysfunction. ${ }^{2}$ Visual symptoms occur in approximately $25 \%$ of patients with preeclampsia. ${ }^{3}$ Visual complications can include cortical blindness, central retinal vein occlusion, vitreous hemorrhage, and retinal detachment. ${ }^{3}$ Retinal detachments are estimated to occur in up to $3 \%$ of patients with preeclampsia. ${ }^{3}$ These retinal detachments are typically exudative and are caused by an accumulation of fluid beneath the retina. In contrast, the majority of retinal detachments seen in the emergency department (ED) are rhegmatogenous, which are caused by retinal holes or tears. This difference in pathophysiology explains why preeclamptic patients with retinal detachments typically do not report flashes or floaters, and typically have improvement in their vision after delivery.

The association between preeclampsia and bilateral retinal detachments has been previously described; however, we could find no reported cases in the emergency medicine literature. ${ }^{4-8}$ Bilateral retinal detachments have also been reported in association with serum sickness, ${ }^{9}$ cytomegalovirus retinitis, ${ }^{10}$ carotidcavernous fistula, ${ }^{11}$ Marfan syndrome, ${ }^{12}$ and nonaccidental pediatric injury ${ }^{13}$. In this case, the finding of bilateral retinal detachments, in combination with an elevated blood pressure, is what prompted us to consider the diagnosis of preeclampsia in a patient who did not know that she was pregnant.

The use of ocular POCUS allowed us to quickly diagnose bilateral retinal detachments, despite an indeterminate fundoscopic examination. Fundoscopy in the ED can often be challenging due to patient and equipment factors. Recently there has been increasing 
evidence supporting the use of ocular POCUS by emergency physicians. Ocular POCUS has been shown to be a useful tool for diagnosing many important conditions, including retinal detachments, vitreous hemorrhage, papilledema, lens dislocation, and globe rupture. ${ }^{14}$ Ocular ultrasound is considered to be safe, and no adverse effects have been reported. However, due to theoretical concerns about heat generation near the retina, scanning time should be minimized, ocular presets using lower energy settings should be used if available, and the use of colour Doppler should be avoided. In addition, it is important to avoid applying pressure on the globe if there is any suspicion of a globe rupture.

The technique for ocular POCUS is relatively easy to learn and perform. In our case, the ultrasound was performed by a junior emergency medicine resident with no prior ocular ultrasound training, under the supervision of a staff physician experienced with the technique. Ocular POCUS is commonly performed using a high-frequency linear array transducer placed gently over the closed eyelid. A generous amount of gel should be used and the operator should stabilize their hand to avoid any pressure on the globe (Figure 2). The anatomic structures visible using ultrasound are shown in Figure 3. The retina should be evaluated by sweeping the transducer in both the longitudinal and transverse orientation at both low and high gain. If a vitreous lesion is identified, a dynamic assessment should be performed by asking the patient to move their eyes from side to side to evaluate its mobility and attachment to the optic nerve.

On ultrasound, a retinal detachment appears as a thick, bright, echogenic line in the vitreous body, which is tethered posteriorly to the optic nerve. Retinal detachments must be differentiated from posterior vitreous detachments, which are more mobile, less echogenic, and are not tethered to the optic nerve. A recent systematic review of the literature on POCUS for the diagnosis of retinal detachments reported a sensitivity between $97 \%-100 \%$ and a specificity between $83 \%-100 \% .{ }^{15}$ However, the combined sample size was small, with a total of only 201 patients; further research is needed to confirm this study's findings and to determine the accuracy of POCUS for detecting small retinal detachments and tears.

The treatment of retinal detachments caused by preeclampsia is aimed at the underlying condition, including blood pressure control, seizure prophylaxis

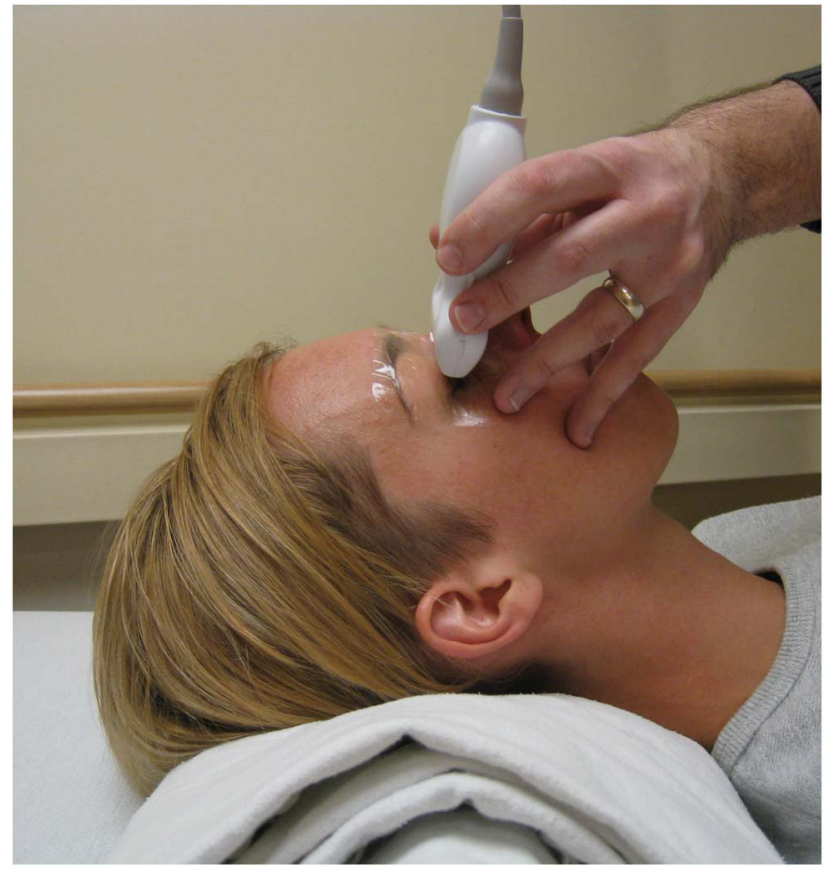

Figure 2. Proper transducer positioning for ocular point-ofcare ultrasound. A generous amount of gel should be applied to the closed eyelid. An optional clear adhesive plastic film may be applied prior to the gel application. The operator's hand should be stabilized by placing their fingers on the patient's cheek or nose.

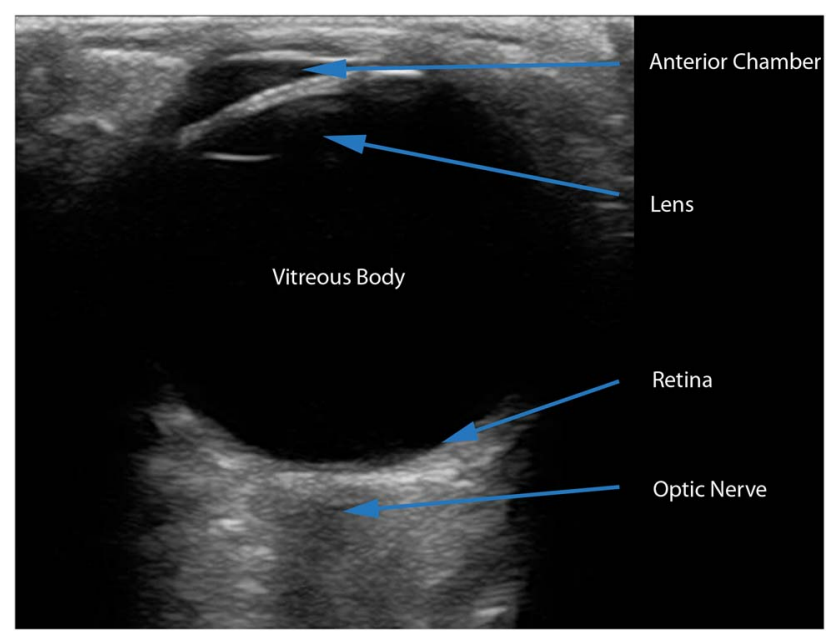

Figure 3. Ocular structures visible using ultrasound include the anterior chamber, lens, vitreous body, retina, and optic nerve.

with magnesium sulfate, and urgent fetal and placental delivery. With appropriate treatment, the visual prognosis is good, with most patients regaining full visual acuity within weeks. ${ }^{3}$ 


\section{CONCLUSION}

Preeclampsia is a life-threatening condition that frequently presents with non-specific signs and symptoms. Emergency physicians should be aware of the association between severe preeclampsia and visual complications, including retinal detachments. In the case presented in this report, the identification of bilateral retinal detachments using POCUS quickly allowed us to refine the differential diagnosis and arrive at an unlikely cause-severe preeclampsia in a patient who did not know that she was pregnant. Preeclampsia should be considered in any woman of child-bearing age who presents to the ED with new onset of visual symptoms and elevated blood pressure.

Competing Interests: None to declare.

\section{REFERENCES}

1. Steegers EA, von Dadelszen P, Duvekot JJ, et al. Pre-eclampsia. Lancet 2010;376(9741):631-44.

2. Magee LA, Pels A, Helewa M, et al. Diagnosis, evaluation, and management of the hypertensive disorders of pregnancy: executive summary. 7 Obstet Gynaecol Can 2014; 36(5):416-41.

3. Roos NM, Wiegman MJ, Jansonius NM, et al. Visual disturbances in (pre)eclampsia. Obstet Gynecol Surv 2012; 67(4):242-50.
4. McEvoy M, Runciman J, Edmonds DK, et al. Bilateral retinal detachment in association with preeclampsia. Aust $N$ Z 7 Obstet Gynaecol 1981;21(4):246-7.

5. Chan WM, Li EK, Chan AY, et al. Bilateral retinal detachment in a young woman. Lancet 2003;361(9374):2044.

6. Srećković SB, Janićijević-Petrović MA, Stefanović IB, et al. Bilateral retinal detachment in a case of preeclampsia. Bosn $\mathcal{Z}$ Basic Med Sci 2011;11(2):129-31.

7. Maslovitz S, Lessing JB, Kupferminc MJ. Bilateral retinal detachment in preeclamptic women with thrombophilia. Int 7 Gynaecol Obstet 2005;91(1):65-6.

8. Chen KH, Chen LR. Bilateral retinal detachment with subsequent blindness in a pregnant woman with severe preeclampsia. Taiwan 7 Obstet Gynecol 2013;52(1):142-4.

9. Howsam G. Bilateral retinal detachment: Following serum sickness. Am 7 Ophthalmol 1965;60(1):141-2.

10. Broughton WL, Cupples HP, Parver LM. Bilateral retinal detachment following cytomegalovirus retinitis. Arch Ophthalmol 1978;96(4):618-9.

11. Cogan JF. Bilateral retinal detachment following carotidcavernous fistula. Br 7 Ophthalmol 1960;44(3):185-8.

12. Dotrelova D. Bilateral retinal detachment in Marfan's syndrome. Eur 7 Ophthalmol 1998;8(2):102-5.

13. Padrón Pérez N, Díaz-Cascajosa J, Prat-Bartomeu J, et al. Bilateral retinal detachment in a case of nonaccidental trauma. Can 7 Opbthalmol 2013;48(3):e44-5.

14. Blaivas M, Theodoro D, Sierzenski PR. A study of bedside ocular ultrasonography in the emergency department. Acad Emerg Med 2002;9(8):791-9.

15. Vrablik ME, Snead GR, Minnigan HJ, et al. The diagnostic accuracy of bedside ocular ultrasonography for the diagnosis of retinal detachment: a systematic review and meta-analysis. Ann Emerg Med 2015;65(2):199-203.e1. 